LAW, ETHICS AND MEDICINE

\title{
Private or intimate relations between doctor and patient: is zero tolerance warranted?
}

\author{
W Spiegel, T Colella, P Lupton
}

$J$ Med Ethics 2005;31:27-28. doi: 10.1136/jme.2003.007385

This article reviews and comments on the five categories of arguments used to defend zero tolerance with regard to sexual contacts resulting from the physician-patient relationship as summarised by Cullen. In addition it puts forward a hypothesis - "fear of loss by third party" - as a psychological explanation for the collective insistence on a zero tolerance policy.

See end of article for authors' affiliations

Correspondence to: Dr W Spiegel, Department of General Practice, Institute of Medical Education, Medical University of Vienna, Thaliastrasse 102/9, A-1160 Vienna, Austria; wolfgang.spiegel@ meduniwien.ac.at

Received

16 November 2003

Accepted for publication

16 December 2003
$\mathrm{F}$ ive arguments put forward for a "zero tolerance policy" with regard to sexual contacts resulting from the physicianpatient relationship (PPR) have been summarised by Cullen, ${ }^{1}$ who, we believe, has also hinted at their weaknesses. There is the "empirical" claim that such contacts are "almost always harmful to the patient".2 It has been well established that any abusive intimate relationship, including those with healthcare professionals, can cause serious psychic harm. But the evidence in support of the "almost always harmful" argument regarding sexual contacts resulting from the PPR consists mainly of case reports and small case series of patients receiving psychotherapy. Of course, no representative studies are known. There is no evidence to suggest that harm following a failed relationship resulting from the break up of a relationship with a non-health professional. ${ }^{3}$ Personally we do not doubt that intimate relationships between doctor and patient have the potential to be harmful to patients, as is the case in any other interpersonal relationship, and can have negative effects on patients' future ability to establish a trusting relationship with a doctor.

The second argument considered by Cullen is the "principles based approach" which is to list the relevant underlying ethical principles and examine whether the proposed course of action is consistent with each of them. The widely acknowledged preconditions, as proposed by Zelas, are trust, power balance, and consent. ${ }^{4}$ Cullen states that this principles based approach is very often abused to argue against intimate relations developing from the PPR in such statements as "due to the position of power the physician brings to the doctor-patient relationship, there are NO circumstances in which sexual activity between a physician and a patient is acceptable". He adds that even when trust, power balance, and consent are accepted as necessary conditions it is possible to think of circumstances where all the three are satisfied. with a health professional is any different to that
We not only agree that this principles based argument is frequently misused but, as regards the power balance issue, would go one step further and ask: is power balance really essential? As we see it, in any relationship of trust, power balance is dispensable! Any genuine relationship, including the PPR, is based on the process of becoming aware of the other, so that a tangible intermediate ("gestalthaftes Zwischen") arises and the necessity for any power balance is not given. In addition, we think that in an age when the paternalistic PPR model is rapidly giving way to informative, interpretative, or deliberative models the imbalance of power has dramatically diminished.

The third, "virtues based", argument suggests that the virtues ethicist considers the virtues necessary in a good doctor and attempts to demonstrate that a virtuous doctor cannot enter into a sexual relationship with a patient. Cullen criticises that this argumentation twists the concept of virtues until virtues become duties to be followed regardless of circumstances. We would add that when advice on how to act is based merely on virtues, the principles of action may be out of touch with individual reality-for example, with the professional framework conditions of practising primary care physicians, and may lack contact with the cultural environment.

The fourth category of arguments identified by Cullen used to defend zero tolerance is the "a priori" reasoning. Its proponents argue that the PPR is defined as displaying certain properties; the PPR must have "property $X^{\prime \prime}$ (emotional distance and detachment). Sexual contact cannot have "property $X^{\prime}$. Therefore, patients cannot be sexual contacts. According to Cullen the question of whether there is something about a PPR that is inconsistent with a sexual relationship is not a matter of fact but of meaning. We think that to demand affective neutrality and detachment between doctor and patient is a contradiction in terms and disregards professional principles, in particular those applied in specialities requiring a PPR of a close and personal nature. This a priori approach could be classified as presumptuous. It is often chosen by theoreticists who have little understanding of the professional framework conditions of, for example, practising family physicians in a rural environment.

Cullen calls the fifth argument "counterfactual". Its proponents argue that if sexual contact between doctors and patients were allowed then there would be unacceptable consequences. A

Abbreviations: PPR, physician-patient relationship. 
typical unacceptable consequence would be the breakdown of the trust essential to a PPR. The argument asserts that the consequences of a policy that allowed sexual contact between doctors and patients would be harmful because patients would have to fear being molested. Can right thinking and right feeling ever be enforced? If right doing has to be enforced, would it not give rise to fears on the part of patients that laws might be broken? We think that a policy which, instead of choosing an educational approach, relies on prohibition is likely to undermine the patient's trust in his/ her doctor, as patients are thereby prompted to think that, but for such prohibition, their doctor could lose control of any sexual arousal he might feel. But there might be a psychological explanation for the collective insistence on a zero tolerance policy.

\section{"FEAR OF LOSS BY THIRD PARTY": PSYCHOLOGICAL MOTIVE FOR THE CRIMINALISATION OF INTIMATE PHYSICIAN- PATIENT RELATIONS}

Although possessionary claims and fears of loss are rarely openly admitted, in every interpersonal relationship they are a potential cause of conflict. This results in partly unconscious territorial behaviour, aimed at warding off potential rivals. The physician, who for the purpose of exercising his/ her profession is allowed to cross physical and social boundaries, is at times instinctively perceived by partners or family members as a potential rival. This becomes obvious in anecdotal reports on the behaviour of some Muslim men, who accompany their wives to the doctors and ask to be present in the room during the consultation. Spouses of patients develop suitable mechanisms of defence in order to control their natural territorial behaviour towards the doctor. A proven collective strategy for coping with this phenomenon, which we term "fear of loss by third party", is the creation of social and medico-legal barriers. It is easier to obligate physicians to decent behaviour by threatening them with social and professional ostracisation than to trust in their ethical capacity to resist taking advantage of emotions resulting from a PPR. As nearly every member of our society may, at some time or other, experience fear of loss regarding someone close, there is a collective interest towards declaring doctors asexual beings and supporting a zero tolerance policy.

The history of prohibition is a long one and rarely has to report successes in cases where attitudes or behaviours were supposed to be enforceable. According to Leggett the injunction against sexual intimacies still functions to preserve the good name of the healing professions. ${ }^{5}$ Others have written urging that although such responses may be appropriate, they should be the outgrowth of serious considerations and open minded contemplation of the ethical, moral, and therapeutic issues involved. ${ }^{6}$ We would like to stimulate debate on how doctors and therapists should handle sexual feelings towards patients and whether there is adequate cause for the injunction prohibiting any sexual relationships with patients and for its enforcement by ethical and disciplinary bodies. We look forward to a social climate where the doctor, when experiencing a feeling of personal affinity with a patient, is encouraged to reflect on it so as to identify restricting factors and possible consequences. Patients may not understand the ethics or the potential harm involved in a doctor-patient social or sexual relationship, but the doctor should. ${ }^{5}$ We have summarised elsewhere important factors to be taken into account when considering initiation of a romantic relationship with a patient. ${ }^{7}$

\section{ACKNOWLEDGEMENTS}

We would like to acknowledge that the opinions expressed are the views of the authors and are not to be construed as reflecting the views of the institutions the authors are affiliated with.

\section{Authors' affiliations}

W Spiegel, Department of General Practice, Institute of Medical Education, Medical University of Vienna, Austria

T Colella, Lainz Hospital, Vienna, Austria

P Lupton, Social philosopher (retired), Bognor Regis, UK \& Vienna, Austria

\section{REFERENCES}

1 Cullen RM. Arguments for zero tolerance of sexual contact between doctors and patients. J Med Ethics 1999;25:482-6.

2 Fahy T, Fisher N. Sexual contact between doctors and patients. BMJ 1992;304:1519-20

3 White GE, Coverdale JA, Thomson AN. Can one be a good doctor and have a sexual relationship with one's patient? Fam Pract 1994;11:389-93.

4 Zelas K. Sex and the doctor-patient relationship. NZ Med J 1997;1 10:60-2.

5 Leggett A. Origins and development of the injunction prohibiting sexual relationships with patients. Aust N Z J Psychiatry 1995;29:586-90.

6 Van Einde Boas C. Some reflections on sexual relations between physicians and patients. J Sex Res 1966;2:215-18.

7 Spiegel W, Colella T, Lupton P. Sexual feelings in the physician-patient relationship: recommendations for teachers. Med Educ 2003;37:840-1. 